\title{
The New Vocabulary of Resilience and the Governance of University Student Life
}

\author{
KATIE AUBRECHT \\ Nova Scotia Centre on Aging, Mount Saint Vincent University, Canada
}

ABSTRACT This article examines the governance of student life in university settings through an examination of discourses of wellness and resilience in the university sector, and in particular at the University of Toronto. Resilience, it is argued, is strategically deployed in ways that enjoin students to think positively about their experiences of university life so as to avert any experience of distress or disability. This is undertaken with the aim of producing a healthy and 'well' student body, but does little to address inequalities amongst students, nor how such inequalities might be important in addressing student distress. Focusing on an analysis of the University of Toronto Student Life Programs and Services programs and publications, and in particular pamphlets and newsletters, such as Health \& Wellness: Helping Students Make the Most of the University Experience (2009), it seeks to understand the role of resilience in the production of student life and the governance of the university experience. The purpose of this analysis is to examine the possibilities and limits of a new vocabulary of resilience (Seligman, 2009), which posits an expectation of suffering as a resource which can be drawn on in times of stress, and the "positive" disciplinary regimes this vocabulary enforces. This examination is carried out with the overall aim of disrupting unexamined relations to representations of institutional sites and services as resources, and to demonstrate how such representations rely on and reproduce notions of difference, disability and distress as difficulties to be both renounced and exploited. It is also to provoke greater recognition within social justice studies of how university health services texts such as the Health \& Wellness pamphlet and newsletters directed at students strategically deploy notions of resilience to govern interpretations of resistance as illness, rather than emancipatory action.

\section{Introduction}

There is the growing sense in the university, and popular culture, that mental illness in students is not only "normal," but a fact of life. The proliferation of discourses on a "hidden problem" (Tamburri, 2012) and even a "crisis" 
(Dehaas, 2011) in student mental health and illness is helping it to become one of the dominant modes of interpreting and negotiating student survival and success. At the University of Toronto, a major cosmopolitan university in Toronto, Ontario, Canada with more than 75,000 students across three campuses, as with many other universities throughout North America and the westernized world, faculty, staff and students are now receiving frequent formal and informal instructions to view student services as a valuable and necessary tool in the preservation of academic standing, not only for students individually, but for the University as a whole.

University health and wellness publications demonstrate a significant investment in the school of thought advanced by psychologist Martin Seligman (2008) who has pioneered the notions of "positive health," a close derivative of "positive psychology" (Seligman \& Csikszentmihalyi, 2000). Seligman has previously piloted similar programs in schools both in the U.S. and in the U.K., as well as in the United States Army (Howell, 2012). Such notions are now increasingly being taken up in university settings across the globe, in the U.S. (Collopy, 2011), the U.K. (Carter, 2010), Australia (Martin $\&$ Marsh, 2006), Finland (JAMK, 2012), and as will be discussed in detail, the University of Toronto. Vocabularies and models of resilience are now even being embedded in tertiary curriculum (Stallman, 2011). As such, programs and publications aimed at increasing student resilience constitute a case study of the ways in which the new trend in "positive thinking" offers a means for understanding the university as an institution organized by neoliberal governance. A critical analysis of the research of this self-proclaimed "new science" (Seligman \& Csikszentmihalyi, 2000) in action in university health services literature also creates space to reflect on the role of the university in shaping the structures of governance.

There is debate concerning the precise meaning and definition of resilience, but much of the current literature on resilience primarily tends to converge on positive adaptation despite adversity (Bottrell, 2009; Cassen, Feinstein \& Graham, 2008; Goodley, 2005; Mohaupt, 2008; Seligman, 2011; Sriskandarajah, Bawden, Blackmore, Tidball, \& Wals, 2010). P.A. Atkinson, C.R. Martin, and J. Rankin describe this adaptation in terms of a "capacity to recover from extremes of trauma and stress" (2009, p. 137). For Seligman, resilience offers a "new vocabulary" (2009, p. 18) which can redirect the gaze within the discipline of psychology away from the "pathological" and towards the "positive features that make life worth living" (Seligman \& Csikszentmihalyi, 2000, p. 5). He says that his thirty years of scientific research on "learned helplessness" and "learned powerlessness" had positive results: "We have learned not only how to distinguish those who will grow from those who will collapse, but also how to build the skills of people in the latter category" (Seligman, 2011, p. 101). Helplessness and powerlessness, in this formulation, are not matters of social justice, but of individual responsibility and capacities. At the crux of the positive psychology movement is the idea that people can learn to be resilient, if given the skills and encouragement to do so. Based on this belief, university wellness services now see students 
as improvable subjects, capable of resilience. Disability, or the possibility that students might become disabled by the experience of distress or other mental health difficulties, lies at the heart of this. Wellness services implicitly view disability negatively, as something that must be prevented through resilience programming, with the aim of preserving or improving the health of the student body, and thus the academic standing of the university more generally.

I examine how contemporary depictions of university students as resilient subjects exemplify a "transformation in rationales and programs of government" (original emphasis; Rose, 1998, p. 62). For Nikolas Rose (1998) this transformation is one aspect of "the techne of psychology" (p. 62); its "mode of practicing or acting upon the world" (p. 62). A consideration of neoliberal governmentality, or "conduct of conduct" (Foucault, 1988, p. $221 ; 1991$ ), is central to this analysis. Governmentality studies (Foucault, 1997; Rose, O'Malley, \& Valverde, 2006) offer critical conceptual tools for unpacking the historical specificity of our ordinary doings, and for situating the language of health and wellness within contemporary western social, political and economic relations of power (Tremain, 2008). Through my analysis of commonplace texts in circulation at the University of Toronto, I show how, despite a claim to "organize, simplify, and rationalize domains of human individuality and difference" (Rose, 1998, p. 62), the certain mode of thinking that characterizes positive psychology is itself neither internally consistent, nor wholly coherent, but is nonetheless productive of versions of the successful and resilient self both prized and expected within the ordinary orders of university life. This makes it possible to examine the relationship between the current focus on resilience and the demand for a skilled, flexible, and productive labour force characteristic of capitalist economies under neoliberal governance.

I draw on a critical disability studies perspective as a means of exposing these practices, and the ways in which resilience-based programming and publications in the university are aimed, simultaneously, at governing and erasing disability. According to Catherine Kudlick (2003), disability studies is, "an interdisciplinary field dating from the mid-1980s that invites scholars to think about disability not as an isolated, individual medical pathology but instead as a key defining social category on a par with race, class, and gender" (2003, para. 2). Within disability studies, interpretive analysis of disability knowledge is understood "as crucial for understanding how western cultures determine hierarchies and maintain social order as well as how they define progress" (2003, para. 3). Further, a disability studies perspective perceives disability as social oppression, rather merely "a humanitarian, medical, administrative or economic issue" (Oliver, 1984, p. 22). However, for Helen Meekosha and Russel Shuttleworth (2009), "What unites CDS [critical disability studies] theorists is an agreement that disabled people are undervalued and discriminated against and this cannot be changed simply through liberal or neo-liberal legislation and policy" (p. 65).

Through an examination of the University of Toronto pamphlet Health \& 
Wellness: Helping Students Make the Most of the University Experience, and related publications, I consider how a focus on resilience, broadly understood in terms of a "positive adaptation in the face of adversity" (Cassen, Feinstein, \& Graham, 2008, p. 73), is used to justify and conceal exploitative social and economic relations. The biomedical frame in the pamphlet is explicit, but the areas and fields of experience it targets and describes are not intuitively medical. Their presentation in the University of Toronto Health Services literature appeals to a notion of everyday experience as the proper subject of western clinical and applied science and research. This is most visible in the University of Toronto Student Life quarterly publication, The Student Body, Mind, and Spirit, which includes articles on everything from personal relationships, familial estrangement and faith, to note-taking, intoxication, sexuality, and peer-pressure.

The Student Body, Mind \& Spirit newsletters began circulation in 2008. They are circulated within the university community via electronic list serves, the University's Counseling and Psychological Services website, departmental and program coordinators, and University-wide public health workshops. The newsletters halted publication in 2011 with the introduction of the now widely distributed Student Health 101 (Student Health, 2011), a global wellness communication system housed in the US and adopted throughout Canadian university systems. The newsletters, available in print in Student Life offices, posted on bulletins boards and electronically accessible through hyperlinks on University Webpages, targeted students, primarily undergraduate students, with the principal focus of the promotion of academic performance through education about student health and wellness.

Within the newsletters, an article titled, "Investing in Resilience," included a recommendation to think about mental health, and more importantly, to "protect" and "enhance our capacity to enjoy life more fully," through resilience (Vorderbrugge, 2008, p. 2). Another pamphlet produced by Student Life titled, "Build on Your Strengths," opens with the assertion that, "There is no health without mental health" (University of Toronto, 2012). The task of "building strengths" involves learning to: "build resilience," "build healthy relationships," "cope with stress," "understand depression," and "understand anxiety" (University of Toronto, 2012). The description for building resilience illustrates how coping is constructed at the University as an academic task. Coping is represented as a skill that students can use to transcend the difficulties of university life (University of Toronto, 2012). Conceived as such, learning to cope becomes part and parcel of learning to succeed (and in lieu of success, survive) and a strategy for dealing with institutional change. The interest in innovation, creativity and flexibility evident in the strategic objectives of universities throughout Canada and the U.S. (Rhoades \& Torres, 2006) and across much of the western world (de Bary, 2010), construct change as a measure that can be used to assess the success of neoliberal programs and policies. Within a market mentality, change is understood in reductive terms as a technology in the successful reproduction and hegemony of cultural systems. Difference is framed within 
a developmental schema as a mode of adaptation, and one which can be more or less successful given the particular historic and economic conditions of a specific socio-cultural locale.

\section{Framing Resilience in Terms of Health and Wellness}

Because the resilience agenda attempts to prevent distress and disability in all members of a given population, its message must be circulated widely. Resilience and wellness publications in university settings are distributed widely in the student population, with the aim of reaching students experiencing distress, who may experience distress in the future, or who know another student experiencing distress or other barriers to "wellness." Rather than providing direct (and expensive) services to all students, pamphlets, newsletters, and other publications are circulated broadly so as to reach the entire student body, making them a key tool in the resilience agenda. In Collected Papers II: Studies in Social Theory, Alfred Schutz says (1976, p. 82),

[In the common situation] the individual members are at "home," that is, they find their bearings without difficulty in the common surroundings, guided by a set of recipes of more or less institutionalized habits, mores, folkways, etc., that help them come to terms with beings and fellowmen belonging to the same situation.

Pamphlets and newsletters are not merely routine sources of information. Instead, they are historically-situated social phenomenon and a mode of communication which helps students "find their bearings" (Shutz, 1976, p. 82). The pamphlet has come to occupy a central role in attempts to organize and represent university life, so much so that it has been constituted as a selfevident response to questions, concerns, or comments. Within the university, pamphlets and newsletters are routinely viewed as important resources to have and make use of, as well as pathways to other resources, and even other pamphlets. As modes of communication these publications coordinate how the university can be known as a universal experience and a common situation open to surveillance, assessment and evaluation. The pamphlet both preserves and circulates established knowledge of the various locations of authoritative knowledge about the university experience-programs, projects, services, websites, buildings, centres, offices, experts and educational events. In doing so, it standardizes how the university can be experienced in the form of questions of knowing where to go, who to ask, and what to ask for.

The language of Student Life constructs the student body as a focal point of activity, authority and social relations within the university. In its appearance in the pamphlet, vocabularies of resilience map an axis of authority - a principal line of movement that directs the reader to places and resources that can validate their personal university experience. Student Life is a mobile focal point that makes it possible to connect widely dispersed 
centers of activity located within a particular geographic region - in this case, the university campus. The realities of student life become questions which, when asked, give an impression of the University (and university experience) as a coherent unity and cohesive whole: it assembles a population of students.

Wellness-oriented publications attempt to govern student experience with the aspiration of instilling resilience and warding off the experience of disability, so as to create a population of "positively healthy" students. This is undertaken in a broader neo-liberal market context, wherein universities must compete for student enrollment and other resources. In directing public attention to the possibility of success despite the prediction of failure, vocabularies of resilience offer one way to legitimize hegemonic power relations. Vocabularies of resilience operate as insurance for the university against critique that the social organization of everyday life and distribution of resources within the university contribute to suffering and to the appearance and experience of uncertainty (represented as depression and anxiety) in students' lives. In encouraging students to self-monitor, regulate and manage, and in effect, become their own entrepreneurs knowing when and where to seek help and refer others, the language of resilience offers a means of financial (de)regulation within the university. This language is circulated within a context of shrinking resources within the university, wherein more traditional (and labour intensive) pastoral care is difficult to carry out given, for example, growing class sizes, lower staff to student ratios, and the increasingly pervasive use of lower-paid temporary contract lecturers within universities. In other words, these publications exist not only to increase student resilience, but they do so in a broader neo-liberal context.

The University of Toronto Health \& Wellness (2009) pamphlet begins with the following statement:

Wellness refers to one's overall physical, emotional, intellectual, spiritual, social and economic condition, as well as the impact experienced as a result of one's environment and occupation. Wellness does not refer simply to the absence of illness, nor does it suggest that someone with chronic illness can not be and feel well. Most university students share a common goal — academic success. The capacity to learn and be academically successful is greatly influenced by your physical and psychological health.

In the process of securing a relationship between the objective appearance of wellness and the meaning of the university experience, the statement produces a rationale to explain the attitudes and behaviour of the university toward students perceived as unhealthy. The assertion that wellness is "more than the absence of illness" orients the reader to a code for making sense of Student Life. Students appear as students only in so far as they can be recognized as making a positive contribution to the overall wellness of the university environment. Contributions are positive which can be viewed as in explicit accordance with conventional understandings and expectations of the meaning and purpose of the university. In this way, the pamphlet serves as a reminder of the existence of multiple ways of interpreting the university 
experience. However, to be perceived as legitimate members of the university community they must learn how to view themselves, others, and the world as it does. Students who can be perceived as following the University's advice are implicitly acknowledged as worthy of the university's attention and assistance in "helping [them] make the most of the university experience" (University of Toronto, 2009).

This is not to suggest that students are necessarily following the instructions of pamphlets or newsletters, or even reading them for that matter. Nonetheless, university student health and social services literature as found at the University of Toronto and on campuses across this increasingly globalized world are here taken up as expressions of the dominant rationalities and power relations that currently organize consciousness of the university experience, and with it, a belief in the existence of a universal student subjectivity that can be achieved and perfected through an investment in evidence-based promising practices. Such texts can thus be read both as displays of the "relations of ruling" (Smith, 1996) within the University and in this case, the University of Toronto, and as political technologies that shape collective understandings of a relationship between academic performance and student mental health.

At the University of Toronto, although disability and mental illness represent distinct categories of existence and experience, individuals identified as disabled and those identified as "mentally ill" are routinely treated in ways which make them appear "the same but different" (Beresford \& Wallcraft, 1997, p. 66). For University of Toronto Accessibility Services, a unit of the division of Student Life Programs and Services, both categories of student, and the heterogeneous "conditions" they collect, fall under the shared rubric of "chronic illness," which is seen as an unpredictable and emergent, but ultimately controllable, crisis.

Textual representations of disability in textual exemplifications of Student Life orient the reader to a universal and hierarchal conception of student embodiment which privileges what Rosemarie Garland Thomson refers to as the "normate" (1997, p. 8). For Garland Thomson, "The term normate usefully designates the social figure through which people can represent themselves as definitive human beings" (1997, p. 8). The pamphlet relies on and reinforces medicalized knowledge about what constitutes normate embodiment - being and feeling well—within an institutional environment that is structured to produce bodies that do better than well academically. Cultural assumptions concerning the stresses students experience in their effort to do what ordinary university students are expected to do, succeed academically, are negotiated with medicalized knowledge about the limits of the body in relation to the world.

The materialization of stress in and on the study body can thus be read as providing a code for categorizing different types of students. With the help of psychiatric knowledge and practices, the appearance of students that are stressed-out (i.e., for whom the condition of stress obstructs their full participation in the University setting) is readily interpreted as the product of a medically-verifiable undesired differentness in embodiment. The pressures 
of the university setting are depicted as leaving unwanted impressions on students preconceived as having a distorted world view. These imprints, made identifiable in such physiological conditions such as high blood pressure and colds and flu, are interpreted as signs of "wrong" ways of relating to the full meaning of the university experience. Students who are perceived to be 'too sensitive' are assumed to be naturally less-than capable of managing their relations. For them, the world is assumed to appear much larger or smaller than it actually is, making everything seem much closer or further than it is from a more "objective," "realistic," or "positive" perspective. Their appearance as students is therefore bracketed by the recognition of the pathological condition of their "natural" ways of relating, whether these ways are the product of traumatic experience, poor parenting, or bad genes (but never as a matter of social injustices). Knowledge of stress thus marks the body as something remarkable, and remarkably troublesome for academic success. Depictions of student stress posit students' experiences as the natural subject of medical knowledge. Within this domain, students are not marginalized by the institutional organization of the university experience and the neoliberal values of flexibility and productivity it espouses, but by personal deficiencies which place them in a position of a natural disadvantage.

\section{Learning to Stay on Track}

The pamphlet orients the student to experiences of difficulty in meeting the normative demands of university life as a symptom of bodies that are less capable of mediating the reality of the university environment. This produces a communication breakdown, and heralds the need for a language which can bridge the divide between the subjective experiences of individual students and the objective reality of the university environment, "helping students make the most of the university experience" (University of Toronto, 2009). This language is the language of Student Life. Its mantra-discovery, diagnosis, intervention (Michalko, 1998) - interweaves the meaning of university culture with medical knowledge.

Within the discourse on health wellness, which includes the physical, emotional, intellectual, spiritual, social and economic aspects of the university experience, disability appears as an obstacle to the participation of individual students in the collective experience of university culture. Disabled embodiment is perceived as an impediment to a clear view of the university experience in its entirety, a distortion (Michalko, 2002). This perspective, which seeks the disclosure of objective knowledge about student subjectivity and claims its embodiment in student life, provides a means of habituating would-be members of the university community to the increasing institutionalization of space, place and identity.

Through the pamphlet, Student Life Programs and Services introduce students to practices of self-governance which will help mitigate the negative impact disability is assumed to have on disabled students' capacity to be like 
ordinary students. Further, it attempts to prevent the experience of disability precisely by fostering wellness and resilience. It aims to put forward an unambiguous and objective understanding of the meaning of disability as a source of adversity (both for student and university), and a clear view to why feeling and being ordinary matters in the university context.

In the delivery of practical knowledge about stress, and when/where/how stress becomes a problem for students, the pamphlet constitutes disabled students as members of the university community. Their membership, however, is represented as provisional since a continued failure to succeed academically could lead to their expulsion. Further, the membership of disabled students is also represented as contingent on the success of institutional programs and services designed to help them be more like "most students." Taken-for-granted assumptions which view disability as a source of stress, both for disabled and nondisabled persons, and an obstacle to participation, leads to an understanding of disability as a potential cause of mental illness. It is thus that even though no direct or explicit mention is made of disability, disability is brought to life in the appearance of stress, depression and/or anxiety. Disability is implicitly positioned throughout as the negative consequence of a failure to be resilient or well.

Within the language of Student Life, mental illness matters because it prevents students from succeeding academically; because it produces alienation and students who are less-than fully alive, and because it can even result in death. Seligman (2011) proposes optimism as the cure to "learned helplessness" which he also frames as depression and anxiety (p. 102). The task at hand is no longer to locate the cure, but in pandemic fashion, how to "immunize" through positive thinking (Seligman, 2011, p. 102). For Seligman, such a pursuit also contributes to the building of a more resilient psychology, as displayed in the following assertion, "This science and practice [of positive psychology] will also reorient psychology back to its two neglected missions - making normal people stronger and more productive and making high human potential actual" (Seligman \& Csikszentmihalyi, 2000, p. 8). We may do well to consider how disabled and marginalized students figure within an institutional setting oriented by a desire to protect, restore, actualize and enhance normalcy, and what effects such projects can be expected to have on the material and social circumstances of disabled students.

In his analysis of a "prescriptive text" (Foucault, 1990) published by the Australian Law Students Association titled Depression in Australian Law Schools, Matthew Ball (2010) responds to representations of stress as a "central cause of depression" (p. 3) within university environments. According to Ball, "The government of stress in order to pre-empt depression provides the conditions for an extension of government to include the student's study habits and time management practices, and opens a space wherein students are encouraged to become time-managing and disciplined selves, governing their mind and body in productive ways" (Ball, 2010, p. 3). In University of Toronto Health Services literature, depression and anxiety provide landmarks of students embodying the tensions of the university; when and where the 
university is present in the body of the student, at certain times of year when term papers are due and exams must be written.

At the University of Toronto, the perspective of Student Life, presents a medicalized, and bureaucratized perspective informed by the language and practices of positive psychology (Seligman, 2008; Seligman \& Csikszentmihalyi, 2000). It relies on professional and supposedly common sense notions of resilience to frame difference in divisive terms. Difference is depicted in terms of deviation from the norm of wellness, and disability as differentness embodied. Disabled students are perceived as inherently alienated, and alienation is understood as an individual problem which can be resolved once the source of this problem can be isolated, identified, and expunged. This is a perspective that invites the reader to understand the University of Toronto's (2010b) presentation of itself in its branding as "Canada's answer to the world's questions" as a product of the superior command with which the University constructs, organizes, and manages its internal divisions. The University's vision of student subjectivity could then be interpreted as the University's response to the question of what a university experience means in a neoliberal political and economic context. The answer it provides relies on the textual erasure of the essential role that biomedical conceptions of difference play in the production of knowledge about student life. The pamphlet inscribes student life with a system of reference points and coordinates interaction, uniformly spaced differences that cross lines of intersections which for normal patterns of thinking, feeling and acting support networks and control of information. The aims of Student Life are inscribed on student life in the reiteration of three simple statements: "What students say...," "What you can do...," and "Why it matters..." (University of Toronto, 2009).

The strategies for coping, managing and adjusting which students bring with them may have to be replaced, discarded, reworked or more finely tuned given the particularities of the university environment. These strategies may also contradict one another. Take, for example, one recommendation to seek out opportunities for self-discovery. It enjoins students to "maintain a hopeful outlook" and "keep things in perspective," while acknowledging that the self that is "discovered" may not coincide with the self that was expected or desired; hence the preceding suggestion to "set realistic goals," and the suggestion which follows: "be ready to give and accept help" (University of Toronto, 2009). This approach models an individualistic and meritocratic understanding of academic failure. It encourages an interpretation of high attrition rates or failures as an indication that students are not working hard enough to maintain the level of health and wellness required for success. According to such an approach it becomes possible to treat students perceived as not participating in the university are represented as self-segregating (Viviene, 2011), and to address the problem of non-participation through the introduction of online resilience training modules students can access from home (Ryan, Shochet, \& Stallmen, 2010). Hence, no need for radical change or revolution. 
In the Student Life pamphlets and newsletters, descriptions of the prevalence, and therefore unexemplary character of the challenges students face, provide for the production of knowledge about what students can do within the university environment. One thing that students can do is mediate the presence or absence of a range of influences which can negatively impact perception of the university experience. Representations of disability as a "challenge," "demand," and "stress" occasion conversations on a necessity to monitor, manage, and control the university experience. When disability "happens," it produces an impact which has the potential to derail students from the institutional pathways to success. At the same time, with the "help" of Student Life Programs and Services students can ostensibly learn how best to recognize and respond to troubling displays of a disruption in student life both in themselves and others, and to read those displays as evidence of a deficiency in university experience.

Erving Goffman (1963) suggests that such "advocated codes of conduct,

... provide the stigmatized individual not merely with a platform and a politics, and not merely with instruction as to how to treat others, but with recipes for an appropriate attitude regarding the self. To fail to adhere to the code is to be a self-deluded, misguided person; to succeed is to be both real and worthy, two spiritual qualities that combine to produce what is called "authenticity." (p. 111)

Where for most students academic success is perceived as the common goal, expectations for students who are recognized as off-track are conceivably lower. For the University to measure its progress towards its outcome goals, students who are not excelling academically are placed in a separate category. Perception of students placed in this category is structured by a normative assumption that they are only capable of meeting the minimum standards of achievement, and will not succeed academically. This type of student appears against the backdrop of preconceived notions about what most students are capable of achieving. Once categorized this way, both the student identity and the disabled student's membership in the university community become precarious.

As a critical disability studies perspective has illustrated, it is not disability per se that is the barrier, but the ways in which university life constitutes barriers for disabled students that is at issue. We need to question what resilience means. Disability studies researcher Dan Goodley (2005) suggests that disabled people have shown resilience in the face of a "disabling world" (p. 334). According to Goodley, "resilience often exists despite disablement, outside self-advocacy groups and in response to disabling community" (p. 333). How resilience is conceptualized is central to building interventions. Rather than building resilience, per se, Dorothy Bottrell (2009) situates resilience in relation to social inequities and social processes in an attempt to address what she understands as a lack of theorizing of resilience. Resilience is not just "common sense" (Daniel, Wassell, \& Gilligan, 1999). It is a historically contingent western construct inseparable from processes of industrialization, modernization, and neoliberal capitalism. Recognizing this, 
Bottrell (2009) advocates for alternative understandings of resilience which challenge normative and individualizing assumptions that define marginality in terms of vulnerability and disadvantage. For Bottrell, critical theorization of the socio-political and economic contexts within which resilience is takenup and practiced conditions the possibility of recognizing resilience as a recent invention, and redefining it in collective terms as resistance, protest, and a question of social justice. And yet, the desire for or development of a theory of resilience is only the beginning, given that, "[m]ainstream resilience theory may readily be incorporated into neoliberal policy emphasis on individual responsibility for coping, competence and success, largely defined in terms of enterprise and contribution to economic rather than social well-being" (Bottrell, 2009, p. 334).

\section{Resilience and the Restoration of Normalcy}

Within the language of Student Life, images of disability which treat disability as a metaphor for difficulties in learning, living, and succeeding, constitute desire for academic excellence as the 'common denominator' in student lives. All students are assumed to want the same thing, academic success, but from the perspective of Student Life some students are naturally predisposed with an inability to realize their desire.

The biomedical assumptions about disability as a deficiency in the overall condition of individual bodies in Health $\&$ Wellness provide an effective way to rationalize differences in academic performance as individual problems. Even when the predisposition is not directly attributed to a pre-existing genetic "disorder," biomedical knowledge and practices at the basis of a psychiatric approach to embodied difference provide a way to make people perceived to have a wrong way of experiencing the world, right. The promise of biomedicine to make right is expressed in the pamphlet's assertion that the negative impact of unhealthy attitudes and behaviours can be mitigated by students" deferral to "services on campus" that can "assist them in getting back on track" (University of Toronto, 2009). Before this promise can be fulfilled, and the student returned to a correct course of action within the relegated domain of university procedure, a clear view of disability as obstruction must be established.

This understanding, however biomedical, anticipates meritocratic forms of governance. If powerlessness is something learned, it is something which can and should be unlearned. Where failure is treated as a question of knowledge of correct action, bodies perceived as having the knowledge and power to overcome failure and powerlessness, and yet still fail to achieve power become perceivable as hopeless cases. The pamphlet can thus be read as a blueprint that structures how challenge is to be perceived and understood in a way that will provide for its reversal: challenge is conceptualized as an opportunity to demonstrate what you can do, and with it, the right to act. This blueprint guides students toward locales within the university environment 
which it claims can provide perspective on the common goal of academic success.

The aforementioned "ensemble of practices" (de Certeau, 2002, p. 11) delivered with and through the pamphlet, authorizes the command of a biomedical approach to knowing the student body. It guides the reader towards the understanding that following the paths inscribed by Student Life with "Health \& Wellness" will lead students to a place where they can exert mastery over the university environment through the realization of the norm. Students are directed to offices, departments, programs, services and resources in and with the help of which they are supposed to gain a new perspective on their situations. However, before they can make good use of the services designed to "help" them, they must first and foremost find their way back to the grid.

The student who is well is perceivable on the basis of the student's doing better than well academically. Doing well despite adversity, and perhaps even because of it shifts attention and labour from protesting inequitable social structures and systems, toward projects aimed at facilitating student adjustment to these structures. The issue becomes one of navigation and adaptation, of knowing where to go and what to expect so that one is not only prepared for disappointment, but prepared to make the most of it. These resilience models ask students to change their perspective on their situations, but never their situations. Here, positive thinking trumps political action. This sets the resilience agenda in direct opposition to any kind of social justice. Students are taught to accept and think positively about their situations, rather than try to change them.

An article in The Student Body, Mind and Spirit titled, "Beyond Language" (Hyland, 2009) portrays mental illness as something that can happen to anyone. It includes the assertion that, "Mental illness does not discriminate; it crosses all cultural, economic and social divides" (2009, p. 3). In doing so, it organizes a conception of adversity as a neutral, non-political entity that "does not discriminate." This understanding is also reflected in another article, "Where Does Your Story Begin," which provides eight strategies for "coping with the transition to University": 1) develop your learning skills; 2) seek out people who want to be successful; 3) know where your supports are; 4) get involved; 5) get organized; 6) find rest spaces; 7) recognize the loss; 8) keep an open mind (Garbutt, 2008, pp. 3-4). These pragmatic ways of relating to adversity as something which can be transitioned into and out of offer the reassurance that because mental illness is "highly treatable," with the "professional help" and "early intervention" already at their fingertips, "with some effort" (Vorderbrugge, 2008, p. 4) there is a good probability that students can begin to achieve a greater semblance of a normal healthy, happy and socially productive life. An even greater probability is envisaged if students can learn to do so in "meaningful communities" (Haworth, 2009, p. 3). 


\section{Conclusion: What is Resilience Doing?}

Treating university health services pamphlets and newsletters as technologies in the production of university students as resilient subjects (O'Malley, 2010) can illustrate how the redistribution of resources under the auspices of social justice is rife with unintended consequences, and necessarily relies on and reproduces cultural assumptions, stereotypes, stigmas and distinctions couched in western neo-liberal values of autonomy, agency, self-sufficiency, independence, and personal strength. I considered how vocabularies of resilience in such ordinary and overlooked texts as health services pamphlets and newsletters produce a version of the individual student as entrepreneur, and social location as something which can be enhanced and overcome through hard work and ingenuity. These vocabularies rely on a depoliticized notion of power as something that can be recovered through positive thinking and selfcare. Positive psychology illustrates how notions of empowerment become bound up and enmeshed in neoliberal agendas. A critical analysis of this selfproclaimed "new science" (MacDonald \& O'Callaghan, 2008; Seligman \& Csikszentmaihalyi, 2000) raises some very important questions concerning the direction in which university governance is headed, particularly with respect to the potential pathologization of resistance.

Discourses of resilience teach students that contemporary neoliberal normalcy can help them negate the damaging potential of a disability identity, what Goffman (1963) refers to as "stigma." Not only is it true that students can survive adversity, but thrive off of adversity through the adoption of positive thinking and the investment in meaningful communities and productive identities. All they have to do is build social capital, diversify their portfolios, and learn how to organize their activities, experiences and attachments in ways that will help them cope with adversity in more socially productive ways. Fitting within the frame of resilience as something which can and ought to be learned in order to survive requires that students accept medicalized definitions of situations. Within this frame student anguish, resistance, distress and dissent can be collapsed and rationalized as the outcomes of a lack of learning or common sense, and a symptom of an inherently inferior subject position. Rather than a consequence of the exploitative conditions that organize how higher learning gets done within the context of a competitive labour market productive of surplus peoples, distress is perceived as living proof of the need for flexible relations to adversity as a problem that can be accommodated through restructuring and adjustment. Vocabularies of resilience promote a notion of adversity as an opportunity for individuals to demonstrate that they know how to make the most of their experiences. Adversity thus understood, occasions the appearance of new, perhaps more efficient and economical relations to increasingly scarce resources. In this way, university students who experience distress, or are identified as distressed, are constructed as inflexible and maladjusted and as such, naturally prone to experience life as a strain (Stewart, 1994). Their grievances are therefore to be interpreted as a symptom of their conditions 
and judged differently than students who are perceived to embody, or at least resemble, normative ideals of productivity.

In a review of the literature on resilience and social exclusion Sarah Mohaupt (2008) shares her finding that the core word of resilience is "resilo," which means to jump back (2008, p. 63). This is in line with the dominant way of understanding resilience as bouncing back from adversity. The Health \& Wellness pamphlet and Student Body, Mind and Spirit newsletters, however mundane, banal, ordinary and inconspicuous, are cultural productions by which student readers should not only be taken aback, but from which we should jump back and reconsider our normative attitudes about the good of life as usual. A critical reading of resilience illustrates how powerlessness and helplessness are not merely attributes which can be learned, and potentially overcome, as Seligman (2011) suggests, but conditions of neoliberal governance. This raises the important issue of whether and how the university represents a living laboratory for testing new techniques in sustainable governance. Wellness publications and programs in the university should thus be viewed as attempts to work not only on student subjectivity, but also as techniques for governing the meaning and experience of difficulty and distress. Instead, we should see embodied and emotional difference as expressions of agency, protest and affirmation, rather than simply signs of passivity, sites of exploitation, or barriers to success that can be overcome through resilience. This shift in perspective, then, is very much a matter of social justice within the university setting, and beyond.

\section{References}

Atkinson, P.A., Marint, C.R., \& Rankin, J. (2009). Resilience revisited. Journal of Psychiatric and Mental Health Nursing, 16, 137-145.

Ball, M. (2010). Governing depression in law students and the shaping of legal personae. In Proceedings of the TASA conference 2010: Social causes, private lives: The American Sociological Association Annual Conference, 6-9 December 2010, Macquarie University, Sydney.

Beresford, P., \& Wallcraft, J. (1997). Psychiatric system survivors and emancipator research: Issues, overlaps and differences. In C. Barnes \& G. Mercer (Eds.), Doing disability research (pp. 66-87). Leeds: The Disability Press.

Bottrell, D. (2009). Understanding "marginal" perspectives: Towards a social theory of resilience. Qualitative Social Work, 8(3), 321-339.

Butler, J. (2004). Precarious life: The power of mourning and violence. London: Verso.

Carter, H. (2010, November 30). College students get resilience training. The Guardian. Retrieved from http://www.guardian.co.uk/education/2010/nov/30/college-students-pressure

Cassen, R., Feinstein, L., \& Graham, P. (2008). Educational outcomes: Adversity and resilience. Social Policy \& Society, 8(1), 73-85.

Daniel, B., Gilligan, R., \& Wassell, S. (1999). “It's just common sense isn't it?” Exploring ways of putting the theory of resilience into action. Adoption \& Fostering Journal, 23(3), 6-15.

de Bary, B. (Ed.). (2010). Universities in translation: The mental labor of globalization. Hong Kong: Hong Kong University Press.

de Certeau, M. (1984/2002). The practice of everyday life (S. Randall, Trans.). Berkeley: University of California Press.

Dehaas, J. (2011). Is there a mental health crisis on campus? Macleans.ca, Retrieved from http:// oncampus.macleans.ca/education/2011/05/27/is-there-a-mental-health-crisis-on-campus/ 
Foucault, M. (1988). Technologies of the self: A seminar with Michel Foucault. L. Martin, H. Gutman, \& P. Hutton, (Eds.). Boston: University of Massachusetts Press.

Foucault, M. (1990). The use of pleasure: the history of sexuality (Vol. 2). New York: Vintage Books.

Foucault, M. (1997). Ethics: Subjectivity and truth. Essential works of Michel Foucault, 1954 1984 (Vol. 1). New York: New Press.

Garbutt, C. (2008, November). Where does your story begin? Student Body, Mind \& Spirit, 1(2): $3 \& 4$.

Garland Thomson, R. (1997). Extraordinary bodies: Figuring physical disability in American culture and literature. New York: Columbia Press.

Goffman, E. (1963). Stigma: Notes on the management of a spoiled identity. London: Penguin.

Goodley, D. (2005). Empowerment, self-advocacy and resilience. Journal of Intellectual Disabilities, 9(4), 333-343.

Haworth, K. (2009, November) Colds, flu and... community? Student Body, Mind \& Spirit, $2(2), 3 \& 4$.

Howell, A. (2012). The demise of PTSD? From governing through trauma to governing resilience. Alternatives, Forthcoming.

Hyland, T. (2009, February). Beyond language. Student Body, Mind \& Spirit, 1(3), 3 \& 4.

JAMK University of Applied Sciences. (2012). Health, wellbeing and resilience. Student Support Services. Retrieved from http://www.jamk.fi/english/forstudents/studyguide/supportservices/ health

Kudlick, C. (2003). Disability history: Why we need another "other." The American Historical Review, 108(3). Retrieved from http://www.historycooperative.org/journals/ahr/108.3/ kudlick.html

MacDonald, M., \& O’Callaghan, J. (2008). Positive psychology: A Foucauldian critique. The Humanistic Psychologist, 36(2), 127-142.

Martin, A., \& Marsh, H. (2006). Academic resilience and its psychological and educational correlates: A construct validity approach, Psychology in the Schools, 43(3), 267-281.

Meekosha, H., \& Shuttleworth, R. (2009). What's so "critical" about critical disability studies? Australian Journal of Human Rights, 15(1), 47-76.

Michalko, R. (2002). The difference that disability makes. Philadelphia: Temple University Press.

Michalko, R. (1998). The mystery of the eye and the shadow of blindness. Toronto: University of Toronto Press.

Mohaupt, S. (2008). Review article: Resilience and social exclusion. Social Policy \& Society, $8(1), 63-71$.

Oliver, M. (1984). The politics of disability. Critical Social Policy, 4, 21-32.

O'Malley, P. (2010). Resilient subjects: Uncertainty, warfare and liberalism. Economy \& Society, $39(4), 488-509$.

Rhoads, R., \& Rhoads, G. (2006). Graduate student unionization as a postindustrial social movement: Identity, ideology, and the contested US academy. In R. Rhoads \& C. A. Torres (Eds.), The university, state, and market (pp. 275-298). Stanford: Stanford University Press.

Rose, N. (1998). Inventing ourselves: Psychology, power and personhood. Cambridge: Cambridge University Press.

Rose, N., O’Malley, P., \& Valverde, M. (2006). Governmentality. Annual Review of Law and Social Science, 2, 83-104.

Ryan, M. L., Shochet, I. M., \& Stallman, H. M. (2010). Universal online resilience interventions might engage psychologically distressed university students who are unlikely to seek formal help. Advances in Mental Health, 9(1), 73-83.

Schutz, A. (1976). Collected Papers II: Studies in Social Theory. The Hague: Martinus Nijhoff.

Seligman, M. \& Csikszentmaihalyi, M. (2000). Positive psychology: An introduction. American Psychologist, 55(1), 5-14.

Seligman, M. (2008). Positive health. Applied Psychology, 57, 3-18.

Seligman, M. (2009, August 28). Mental stress training is planned for US soldiers. New York Times, p. 18.

Seligman, M. (April, 2011). Building resilience. Harvard Business Review, 101-106.

Smith, D. (1996). The relations of ruling: A feminist inquiry. Culture and Organization, 2(2), 171-190. 
Sriskandarajah, N., Bawden, R., Blackmore, C., Tidball, K., \& Wals, A. (2010). Resilience in learning systems: Case studies in university education. Environmental Education Research, 16(5-6), 559-573.

Stallman, H. (2011). Embedding resilience within tertiary curriculum: A feasibility study. Higher Education Research \& Development, 30(2), 121-133.

Stewart, D. W. (1994). Using the MMPI-2 College Maladjustment Scale in a Canadian university setting. Canadian Journal of Counselling and Psychotherapy, 28(2), 135-141.

Student Health 101. (2011). About us. Retrieved from http://www.studenthealth101.com/about us.htm

Tamburri, R. (2012). Universities to examine their role in students' mental health. University Affairs. Retrieved February 6, 2012 from http://www.universityaffairs.ca/universities-toexamine-their-role-in-students-mental-health.aspx

Tremain, S. (Ed.). (2008). Foucault and the government of disability. Michigan: University of Michigan.

University of Toronto. (2009). Health \& wellness: Helping students make the most of their university experience [Brochure]. Student Life Programs \& Services. Retrieved from http:// healthservice.utoronto.ca/pdfs/Health--Wellness-Brochure.htm

University of Toronto. (2010a). Discover U of T: Health + Wellness: Student Crisis Response Programs. Retrieved from http://discover.utoronto.ca/health-wellness University of Toronto (2010b). This is U of T. Retrieved from http://www.thisisuoft.utoronto.ca/Assets/Strategic $+\mathrm{C}$ ommunications + Digital + Assets/This + is $+\mathrm{U}+$ of $+\mathrm{T} / \mathrm{U}+$ of $+\mathrm{T}+$ One+Pagers/Overview.pdf

University of Toronto. (2012). Build on your Strengths. Retrieved from http://www. healthycampus.utoronto.ca/All-About-Wellness/Building-on-Your-Strenghts.htm

Viviene, C. (2011). Resilience, transition and the international student experience in diverse university settings. Leeds Metropolitan University. Retrieved from http://www.srhe.ac.uk/ conference2011/abstracts/0225.pdf

Vorderbrugge, J. (2008, September). Investing in resilience. Student Body, Mind \& Spirit, 1(1), $2 \& 4$. 